\title{
DESAIN LEMBAR KERJA SISWA MATERI BANGUN RUANG SISI DATAR DENGAN MODEL MATEMATIKA KNISLEY BERBANTUAN GEOMETRYX
}

\author{
Puji Nurfauziah ${ }^{1}$, Alwan Fauzy ${ }^{2}$, Nelly Fitriani ${ }^{3}$ \\ 1,2,3 IKIP Siliwangi, JIn. Terusan Jend, Sudirman, Cimahi, Indonesia \\ Email: ${ }^{1}$ zielazuardi@gmail.com, ${ }^{3}$ nhe.fitriani@gmail.com
}

\begin{abstract}
During the Covid-19 pandemic, all learning activities were online and the majority of learning activities were using mobile phones. Therefore, this study aims to produce Student Worksheets (LKS) on build flat side space materials (BRSD) using Geometryx-assisted Knisley mathematical models during the Covid-19 period. The development of LKS is seen as an alternative that will make online learning activities more interesting and interactive. LKS BRSD with Geometryxassisted Knisley mathematical model covers four stages, namely: (1) concrete-reflective; (2) concrete-active; (3) abstract-reflective; and (4) abstract-active. The method in this research is design research conducted in three stages, namely: (1) preliminary design; (2) design experiment; and (3) restrospective analysis. The data obtained from this study came from the validation of two validators and responses from 30 grade VIII junior high school students. Based on the results of the data analysis, it was concluded that LKS BRSD using Geometryx-assisted Knisley mathematical model was on valid criteria and did not need to be revised. LKS BRSD using the Knisley math model assisted by Geometryx received a positive response from students, so it is considered to be able to make mathematics learning meaningful.
\end{abstract}

Keywords: Build flat side space, geometryx, knisley math model, student worksheets

\begin{abstract}
ABSTRAK
Pada masa pandemi Covid-19 seluruh kegiatan pembelajaran bersifat daring dan mayoritas kegiatan pembelajaran menggunakan handphone. Oleh karena itu, penelitian ini bertujuan untuk menghasilkan Lembar Kerja Siswa (LKS) pada materi Bangun Ruang Sisi Datar (BRSD) dengan menggunakan model matematika Knisley berbantuan Geometryx di masa Covid-19. Pengembangan LKS ini dipandang dapat menjadi satu alternatif yang akan menjadikan kegiatan pembelajaran daring menjadi lebih menarik dan interaktif. LKS BRSD dengan model matematika Knisley berbantuan Geometryx meliputi empat tahapan, yaitu: (1) concrete-reflective; (2) concrete-active; (3) abstract-reflective; dan (4) abstract-active. Metode dalam penelitian ini yaitu design research yang dilaksanakan dalam tiga tahap, yaitu: (1) desain pendahuluan (preliminary design); (2) percobaan desain (design experiment); dan (3) analisis restrospektif (restrospective analysis). Data yang diperoleh dari penelitian ini berasal dari hasil validasi dua orang validator dan respon dari 30 siswa kelas VIII SMP. Berdasarkan hasil analisis data, diperoleh kesimpulan bahwa LKS BRSD dengan menggunakan model matematika Knisley berbantuan Geometryx berada pada kriteria valid dan tidak perlu direvisi. LKS BRSD dengan menggunakan model matematika Knisley berbantuan Geometryx mendapatkan respon yang positif dari siswa, sehingga dipandang dapat menjadikan pembelajaran matematika secara bermakna.
\end{abstract}

Kata kunci: Bangun ruang sisi datar, geometryx, lembar kerja siswa, model matematika knisley

Dikirim: 14 Januari 2021; Diterima: 31 Januari 2021; Dipublikasikan: 30 Maret 2021

Cara sitasi: Nurfauziah, P., Fauzy, A., \& Fitriani, N. (2021). Desain lembar kerja siswa materi bangun ruang sisi datar dengan model matematika knisley berbantuan geometryx. Teorema: Teori dan Riset Matematika, 6 (1), 1-11.

Doi: http://dx.doi.org/10.25157/teorema.v6i1.4827 


\section{PENDAHULUAN}

Januari 2020 WHO menetapkan Covid-19 sebagai public health emergency of international concern karena adanya wabah Covid-19, CDC (Tim Kerja Kementerian Dalam Negeri, 2020). Indonesia menetapkan status darurat bencana dan salah satu solusi yang diterapkan oleh Indonesia adalah dengan menerapkan Gerakan social distancing dan tidak melakukan kontak langsung serta menghindari pertemuan massal, CNN Indonesia (Buana, 2020). Oleh karena hal tersebut, salah satu gerakan social distancing adalah dengan penutupan sekolah dan perguruan tinggi untuk mengurangi penyebaran Covid-19 (Unicef, 2020).

Pembelajaran yang dilakukan di sekolahpun otomatis berubah, dari yang asalnya pembelajaran secara tatap muka menjadi tidak tatap muka yang berbasis online. CoSN (2020) menyatakan bahwa perubahan sistem pembelajaran dari lingkungan sekolah menjadi pembelajaran jarak jauh ini merupakan suatu tantangan yang harus membawa siswa dan guru ke luar kelas dengan membutuhkan kerjasama yang erat antara tim pengajaran, konten, dan teknologi. Akan tetapi, pembelajaran pada saat Covid-19 ini menjadi kurang efektif dikarenakan penyampaian guru tidak maksimal ditandai dengan hanya pemberian pekerjaan rumah saja yang menjadikan pemahaman siswa menurun (Apriansyah \& Pujiastuti, 2020). Sehingga banyak siswa merasa bosan dan malas dengan kegiatan pembelajaran jarak jauh atau pembelajaran daring yang dilakukan di rumah saat ini. Maka kegiatan pembelajaran tersebut berpengaruh besar terhadap pemahaman siswa, khususnya mata pelajaran matematika. Khusus pada mata pelajaran matematika, pembelajaran jarak jauh ini agak sedikit berat. Karena matematika merupakan mata pelajaran yang abstrak yang membutuhkan perhatian serius (Lamote, 2017). Hal tersebut dikarenakan di dalam matematika banyak materi yang harus dianalisis, digambarkan, atau dimodelkan.

Belajar tentang belajar matematika berarti belajar mengenai konsep-konsep dan strukturstruktur bahasan yang harus dipelajari keterkaitannya (Abida \& Kusuma, 2019). Salah satu pokok bahasan dalam matematika yang perlu dikaji secara jelas pada saat pembelajaran daring adalah geometri. Geometri merupakan persepsi tentang ruang dan pengembangan persepsi visual mengenai benda-benda pikiran yang sifatnya abstrak seperti kubus, balok, prisma, limas dan sebagainya (Zinnurain \& Gafur, 2015). Konsep geometri yang akan diperdalam dan diperjelas yaitu pada konsep bangun ruang sisi datar (BRSD). Berangkat dari hal tersebut, dipandang perlu ada kegiatan pembelajaran yang menjadikan apa yang dipelajari itu bermakna walaupun pembelajaran dilakukan secara jarak jauh atau online. Oleh karena itu, diperlukan pembaruan di dalam kegiatan pembelajaran mengenai geometri pada saat pembelajaran daring, yaitu dengan memberikan bahan ajar, dalam hal ini lembar kerja siswa BRSD dengan model matematika Knisley berbantuan Geometryx. Lembar kerja yang diberikan kepada siswa dimodifikasi dengan menggunakan model matematika Knisley. Adapun tahapan dari model matematika Knisley yang mengadaptasi gaya belajar Kolb yaitu kongkrit-reflektif, kongkrit-aktif, abstrak-reflektif, dan abstrak-aktif (Knisley, 2002). Geometryx merupakan aplikasi geometri (kalkulator geometri) yang dapat diinstall secara bebas pada smartphone dengan cara mengunduh di google play store.

Google play menjelaskan bahwa Geometryx adalah aplikasi yang diciptakan untuk menyenangkan perhitungan angkaan, padatan geometri serta nilai yang terpenting. Aplikasi menghitung luas, keliling, volume, koordinat pusat gravitasi, ketinggian, panjang sisi, diagonal, panjang segmen, sudut mengukur lateral dan luas permukaan keseluruhan padatan geometri, (https://play.google.com/store/apps/details?id=com.famobix.geometryx\&hl=in\&gl=US). Pada saat ini, hampir semua siswa memiliki handphone. Sehingga kegiatan pembelajaran dengan berbantuan aplikasi Geometryx dipandang dapat dilaksanakan dan menjadi salah satu alternatif media yang digunakan ketika pembelajaran daring, karena siswa dapat mengunduh langsung aplikasi Geometryx. Berdasarkan hal tersebut, tujuan dari penelitian ini adalah untuk menghasilkan lembar kerja siswa materi bangun ruang sisi datar dengan menggunakan model matematika Knisley berbantuan Geometryx di masa Covid-19. 


\section{METODE PENELITIAN}

Metode yang digunakan dalam penelitian ini yaitu design research, dimana prosedur penelitian yang dilakukan meliputi tiga tahapan. Prahmana (2017) mengemukakan tahapan tersebut dibagi dalam tiga tahap yaitu, desain pendahuluan (preliminary design), percobaan desain (design experiment), dan analisis restrospektif (restrospective analysis). Pada tahap preliminary design, kegiatan yang dilakukan adalah menganalisis materi bangun ruang sisi datar serta menyusun dan mendesain LKS berdasarkan hasil analisis materi BRSD serta instrumen validasi LKS. Pada kegiatan analisis dan penyusunan ini terdapat perbedaan dari penelitian-penelitian sebelumnya terkait model matematika knisley, diantaranya model matematika Knisley dilihat sebagai model pembelajaran yang diimplementasikan langsung di kelas (Romadoni, 2016; Haety \& Mulyana, 2013). Dalam penelitian ini, model matematika Knisley dilihat sebagai suatu pendekatan pembelajaran, dimana tahap-tahap dari model matematika Knisley diterapkan langsung ke dalam LKS BRSD.

Pada tahap design experiment dilakukan uji coba dengan cara memberikan LKS BRSD disertai lembar validasi yang disesuaikan dengan indikator penyusunan LKS kepada dua validator yaitu dosen pendidikan matematika dan guru matematika SMP, serta 32 siswa kelas VIII SMP Muslimin Cililin untuk menilai bagaimana pembelajaran dengan menggunakan LKS BRSD dengan model matematika Knisley berbantuan Geometryx. Darmojo \& Kaligis (Salirawati, 2006) menyebutkan bahwa syarat LKS yang berkualitas baik harus memenuhi syarat didaktik, syarat konstruksi, dan syarat teknis. Pada penelitian ini tiga syarat tersebut ditambahkan satu lagi yaitu kesesuaian materi, sehingga indikator validasi yang digunakan yaitu meliputi: kesesuaian materi, syarat didaktik, syarat konstruksi, dan syarat teknis.

Pada tahap restrospective analysis yaitu menganalisis hasil validasi serta masukanmasukan yang diberikan oleh validator dan siswa yang akan digunakan sebagai bahan evalusi perbaikan LKS berikutnya dengan menggunakan rumus dan kriteria yang diadaptasi dari Fatmawati (2016) berikut.

$$
\text { Validitas }(V)=\frac{\text { Total skor validasi } 2 \text { validator }}{\text { Total skor maksimal }} \times 100 \%
$$

Adapun kriteria validitas perangkat pembelajaran menggunakan kriteria menurut Arikunto (2010) disajikan dalam Tabel 1.

Tabel 1. Kriteria validitas perangkat pembelajaran

\begin{tabular}{ccc}
\hline LKS (\%) & Tingkat Kevalidan & Ket \\
\hline $76-100$ & Valid & Layak/ Tak Perlu Direvisi \\
$51-75$ & Cukup Valid & Cuku Layak/ Revisi Sebagian \\
$26-50$ & Kurang Valid & Kurang Layak/ Revisi Total \\
$<26$ & Tidak Valid & Tidak Layak/ Revisi Total \\
\hline
\end{tabular}

\section{HASIL DAN PEMBAHASAN}

Penelitian ini menghasilkan lembar kerja siswa materi bangun ruang sisi datar dengan menggunakan model matematika Knisley berbantuan Geometryx. Penelitian ini melewati tiga tahapan, yaitu desain pendahuluan (preliminary design), percobaan desain (design experiment), analisis restrospektif (restrospective analysis). Pada tahap desain pendahuluan (preliminary design), peneliti melakukan analisis materi BRSD meliputi materi kubus, balok, prisma, dan limas serta menganalisis bagian materi mana yang dianggap mudah dan sulit oleh siswa. Dari tahap analisis tersebut, ditekan bahwa siswa mengalami kesukaran dalam menyelesaikan soal-soal cerita, tidak hafal rumus, serta kesulitan dalam membayangkan bentuk bagun ruang sisi datar (Awwalin, 2021; Tusiah \& Amalia, 2018). Sehingga pada LKS yang didesain dengan menggnakan model matematika Knisley, materi BRSD akan dimodifikasi serta akan ditekankan pada aplikasi permasalahan BRSD. Hal tersebut, ditunjukkan dengan diberikannya banyak soal cerita yang menggiring siswa untuk menemukan konsep berdasarkan dari soal cerita yang berkaitan dengan pengetahuan yang sudah dimilikinya dengan cara membandingkan yang disesuaikan dengan 
tahapan matematika Knisley. Untuk tahap pembuktian dari soal-soal yang diberikan adalah dengan menggunakan aplikasi Geometryx yang dipandang cocok dengan kegiatan pembelajaran di masa pandemi Covid-19 serta disesuaikan dengan indikator penyusunan bahan ajar. Penyusunan LKS didasarkan pada indikator kesesuaian materi, kesesuaian dengan syarat didaktik (memenuhi ciri belajar mengajar efektif), kesesuaian dengan syarat konstruksi (kesesuaian bahasa yang mudah dimengerti dan tepat guna), serta kesesuaian dengan syarat teknis (teknik penulisan yang efisien) (Salirawati, 2006).

Selanjutnya pada tahap percobaan desain (design experiment), lembar kerja siswa divalidisi oleh judgment expert agar memperoleh hasil validasi dari lembar kerja siswa yang disusun sebelumnya, kemudian dijadikan perbaikan sebelum diberikan kepada siswa kelas VIII agar siswa dapat melaksanakan kegiatan pembelajaran di masa pandemi covid dengan menggunakan LKS dengan menggunakan model matematika Knisley berbantuan Geometryx serta siswa dapat memberikan respon terkait bahan ajar yang digunakan oleh siswa. Akhirnya pada tahap analisis restrospektif (restrospective analysis), didapatkan hasil terkait validasi LKS dari judgment expert serta respon siswa dalam menggunakan LKS BRSD dengan model matematika Knisley berbantuan Geometryx. Hasil dari validasi serta masukan dan tanggapan dari siswa dianalisis dan dijadikan evaluasi LKS agar LKS jauh lebih baik dan sempurna, sehingga LKS BRSD dengan menggunakan model matematika Knisley berbantuan Geometryx dapat membantu siswa agar menjadi lebih semangat, dan lebih bermakna lagi di dalam kegiatan pembelajaran dengan bantuan Geometryx. Berikut hasil validasi lembar kerja siswa oleh judgment expert. Salah satu komentar judgment expert disajikan pada Tabel 1 dan Gambar 1.

Tabel 1. Hasil validasi bahan ajar

\begin{tabular}{|c|c|c|c|c|c|c|}
\hline \multirow[b]{2}{*}{ No } & \multirow{2}{*}{ Indikator } & \multicolumn{2}{|c|}{ Hasil } & \multirow{2}{*}{$\begin{array}{c}\text { Rata-rata } \\
\text { Hasil }\end{array}$} & \multirow{2}{*}{ Kriteria } & \multirow[b]{2}{*}{ Ket } \\
\hline & & Validator I & Validator II & & & \\
\hline 1 & Kesesuaian materi & $70 \%$ & $70 \%$ & $70 \%$ & $\begin{array}{l}\text { Cukup } \\
\text { valid }\end{array}$ & $\begin{array}{c}\text { Cukup Layak/Revisi } \\
\text { sebagian }\end{array}$ \\
\hline 2 & $\begin{array}{l}\text { Kesesuaian LKS dengan } \\
\text { syarat didaktik }\end{array}$ & $80 \%$ & $92 \%$ & $86 \%$ & Valid & $\begin{array}{c}\text { Layak/Tidak perlu } \\
\text { direvisi }\end{array}$ \\
\hline 3 & $\begin{array}{l}\text { Kesesuaian LKS dengan } \\
\text { syarat konstruksi }\end{array}$ & $80 \%$ & $88 \%$ & $84 \%$ & Valid & $\begin{array}{c}\text { Layak/Tidak perlu } \\
\text { direvisi }\end{array}$ \\
\hline 4 & $\begin{array}{l}\text { Kesesuaian LKS dengan } \\
\text { syarat teknis }\end{array}$ & $80 \%$ & $83 \%$ & $81,5 \%$ & Valid & $\begin{array}{c}\text { Layak/Tidak perlu } \\
\text { direvisi }\end{array}$ \\
\hline & Total & $77,5 \%$ & $83,25 \%$ & $80,38 \%$ & Valid & $\begin{array}{c}\text { Layak/Tidak perlu } \\
\text { direvisi }\end{array}$ \\
\hline
\end{tabular}

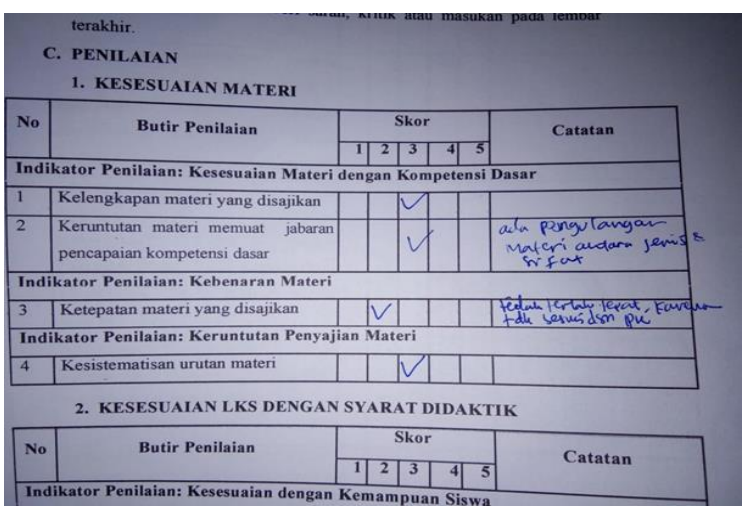

Gambar 1. Komentar validator

Berdasarkan hasil validasi di atas, sebenarnya LKS sudah tergolong baik (dapat dilihat pada Tabel 1). Hal tersebut ditunjukkan dengan hasil validasi yang berada pada kriteria valid dengan interpretasi layak/tidak perlu direvisi. Masukan dari validator pada Gambar 1 terkait keruntutan materi yang sesuai kompetensi dasar serta ketepatan materi yang disajikan di dalam LKS. Pada awalnya, hampir semua LKS berisi soal cerita tanpa adanya gambar ataupun arahan untuk menggambarkan, padahal materi yang dibahas adalah bangun ruang sisi datar, dan menjadi tidak sesuai dengan kompetensi dasar yang 
diberikan. Sehingga peneliti sebelum memberikan LKS kepada siswa terlebih dahulu merevisi LKS sesuai dengan saran dan arahan dari validator, yaitu menyesuaikan materi dengan memodifikasi pertanyaan serta pernyataan yang ada di dalam LKS khususnya pada tahap concrete-reflective dan abstractreflective.

Lembar kerja siswa pada materi BRSD dengan menggunakan model matematika Knisley berbantuan Geometryx terdiri dari 4 tahapan, yaitu concrete-reflective, concrete-active, abstractreflective, abstract-active. Pada tahap pertama, yaitu concrete-reflective siswa diarahkan agar menemukan konsep baru terkait BRSD berdasarkan konsep lama yang mereka miliki/dari pengalaman belajar mereka terdahulu. Sesuai dengan arahan dari validator, bahwa pada tahap ini perlu ada revisi terkait permasalahan dengan cara menyajikan gambar. Knisley (2000) mengungkapkan bahwa concrete-reflective merupakan pembangunan pengetahuan berdasarkan pengalaman yang mereka miliki sebelumnya, dimana mereka akan mengatasi masalah dengan pengetahuan yang telah dimiliki sebelumnya, atau bisa disebut juga dengan Allegorizer. Hal tersebut terdampat pada LKS BRSD yang membahas materi jaring-jaring prisma. Pada tahap concretereflective, siswa diberikan permasalahan untuk me-recall pengetahuan mereka terdahulu terkait prisma dengan cara menyebutkan dua bangun yang berbentuk prisma yang telah mereka ketahui sebelumya yang disajikan dalam Gambar 2.

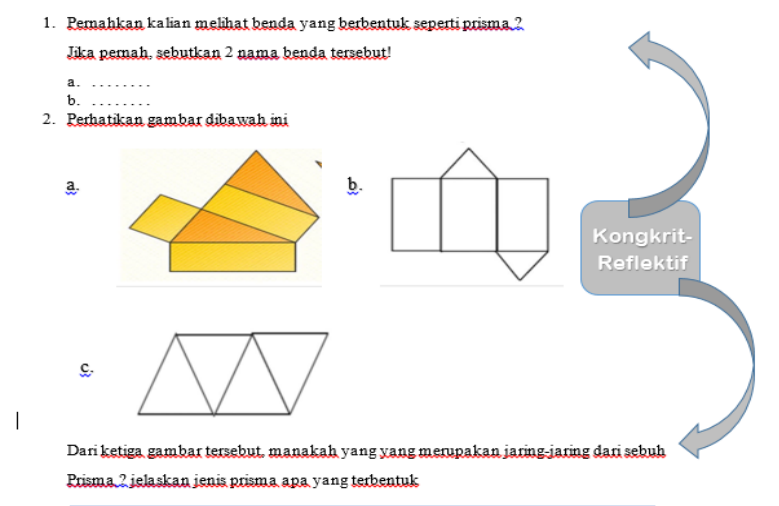

Gambar 2. Tahap 1: concrete-reflextive pada LKS BRSD

Pada tahap ini, siswa akan menuliskan benda yang mereka anggap sebagai prisma, kemudian mereka akan membayangkan dan mencocokkan bagaimana jarring-jaring prisma tersebut disertai dengan alasannya. Siswa akan lebih mudah untuk memahami permasalahan jika dihubungkan dengan pemahaman siswa sebelumnya dan atau dikaitkan dengan kehidupan mereka. Pada tahap ini, siswa tidak memiliki terlalu banyak kesulitan, karena pemasalahan yang disajikan secara kongkrit. Siswa yang kesulitan belajar geometri akan lebih mudah memahami permasalahan geometri jika dihubungkan dengan kehidupan mereka. Hal tersebut sesuai dengan pendapat Allsopp et al. (2007) "When struggling learners are provided opportunities to learn and apply geometry within meaningful, relevant contexts, they are more likely to understand geometric ideas and how they connect to real life".

Selanjutnya adalah tahap kedua yaitu concrete-active, siswa akan belajar dengan cara trial and error atau dengan cara mencoba-coba, dan kemudian mereka akan mulai dengan cara membanding-bandingkan ide sebelumnya dengan yang baru mereka dapatkan. Hal tersebut dijelaskan oleh Knisley (2000) "These students rely heavily on comparisons of new ideas to known ideas. They address problems by relying on their "common sense" insights-i.e., by comparing the problem to problems they can solve". Pada tahap concrete-active, peneliti mulai mengkombinasikan LKS BRSD dengan bantuan Geometryx. Geometryx pada tahap ini dianggap akan sangat membantu tahap trial and error siswa dalam membandingkan ide-ide yang baru didapatnya. Tampilan LKS BRSD berbantuan Geometryx pada tahap concrete-active disajikan pada Gambar 3 dan Gambar 4. 


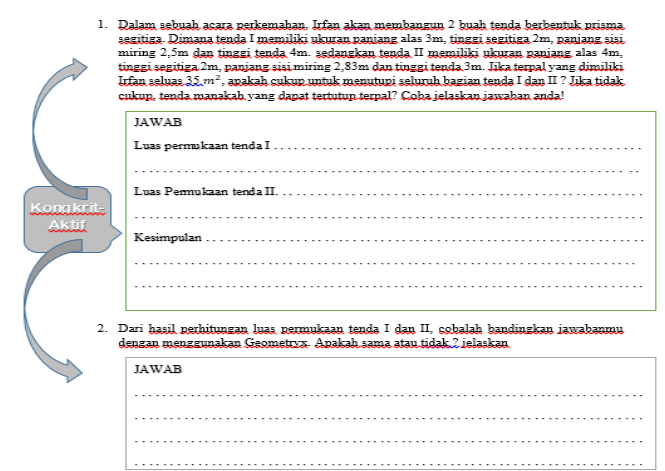

Gambar 3. Tahap 2: concrete-active pada LKS BRSD
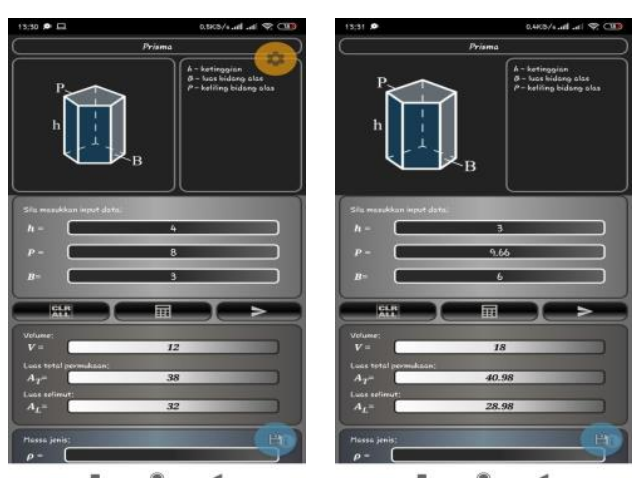

Gämbär 4. Jawaban dari Geometryx

Saat ini, hampir semua siswa memiliki smartphone dari berbagai merk dan spesifikasi. Dengan adanya smartphone, pembelajaran daring akan dipandang sedikit besarnya menjadi lebih mudah, karena siswa dapat mencari sumber belajar/data secara tidak terbatas. Hal tersebut sesuai dengan pendapat White \& Martin (2014) yang mengemukakan "Mobile devices have transformed the ways that people communicate, seek information, and work with data of various forms". Berdasarkan hal tersebut, Geometryx dipandang cocok dalam membantu kegiatan pembelajaran daring yang dilaksanakan. Terlihat dari LKS BRSD pada Gambar 3, siswa diarahkan untuk membandingkan dua tenda yang akan ditutupi terpal. Dari permasalahan tersebut, siswa akan mencoba-coba menjawab sesuai dengan pengetahuan yang ia dapatkan sebelumnya dan pengetahuan yang ia dapatkan pada tahap concrete-reflextive. Setelah siswa mendapatkan jawaban dengan cara trial and error, maka mereka diarahkan untuk mencoba dengan aplikasi Geometryx yang sudah di-install di dalam smartphone-nya. Hal tersebut bertujuan untuk mengecek jawaban siswa dan pengetahuan siswa terkait apa yang telah mereka coba dengan cara trial and error.

Tahap yang ketiga adalah abstract-reflective, pada tahap ini siswa telah mendapatkan konsep yang baru, akan tetapi mereka masih kekurangan informasi terkait apa yang mereka dapatkan dan perlu penjelasan lebih detail lagi. Pada tahapan ini siswa bertindak sebagai analyzer, siswa akan membutuhkan penjelasan logis yang terstruktur dan sistematis untuk memecahkan permasalahannya (Knisley, 2000). Selain itu, siswa akan menganalisis konsep yang telah diberikan dengan memperhatikan aturan-aturan/sistematika yang terstuktur berdasarkan tahapan sebelumnya mengenai konsep yang telah dipelajari (Nurfauziah \& Sari, 2019). Tampilan LKS BRSD berbantuan Geometryx pada tahap abstract-reflective disajikan pada Gambar 5 dan Gambar 6.

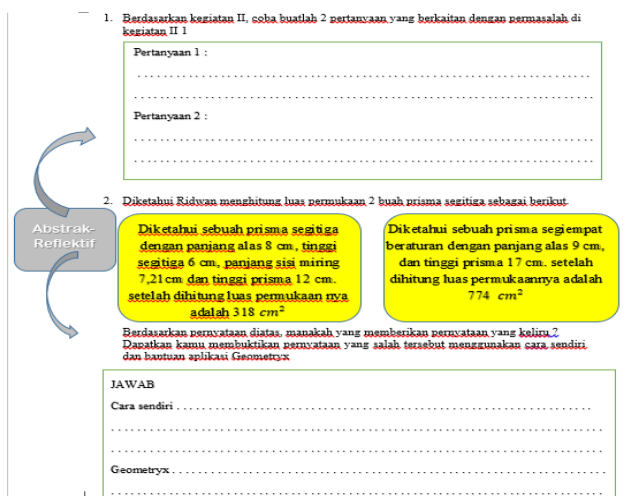

Gambar 5. Tahap 3: abstract-reflective pada LKS BRSD
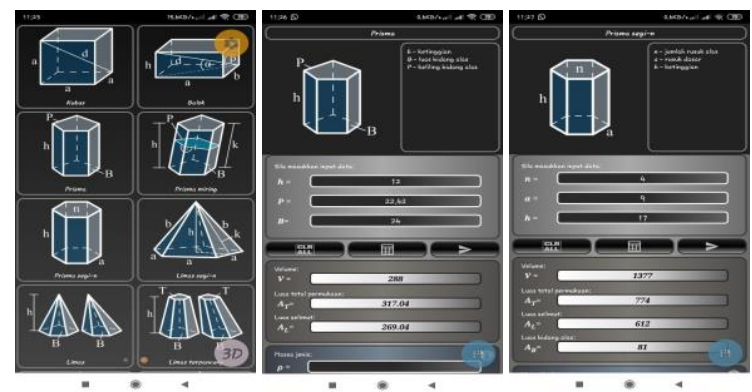

Gambar 6. Jawaban dari Geometryx

Siswa akan menggali informasi lebih dalam lagi terkait penjelasan konsep yang lebih detail pada tahap abstract-reflective dengan cara memberikan pertanyaan-pertanyaan yang disesuaikan dengan kebutuhan siswa. Pada tahap ini siswa akan berpikir kritis dalam mengemukakan 
permasalahan yang masih belum dipahami, sehingga mereka dapat menyelesaikan permasalahan secara terstruktur. Penggunaan Geometryx pada tahap ini sudah disesuaikan dengan permasalahan yang diberikan, agar siswa dapat mengeksplorasi pengetahuannya dengan cara memberikan jawaban yang bervariatif, karena untuk menjawab permasalahan pada Gambar 5, dapat menggunakan Geometryx dengan dua cara.

Pada tahap ini siswa diarahkan agar dapat menemukan formula baru yang mereka dapatkan dari rangkaian tahap-tahap sebelumnya yang telah disajikan di dalam LKS BRSD. Pada tahap keempat yaitu abstract-active, siswa dapat mengeksplorasi jawaban dengan cara yang mereka yakini sendiri. Siswa dapat mengembangkan strategi individu dalam menyelesaikan permasalahan dengan ide-ide yang baru (Knisley, 2000). Pada tahap ini siswa berperan sebagai synthesizer yaitu siswa telah mengetahui ciri khusus dari sebuah konsep dan dapat membuat prosedur penggunaan konsep tersebut dalam memecahkan masalah (Haety \& Mulyana, 2013). Tampilan LKS BRSD pada tahap abstract-active disajikan pada Gambar 7.

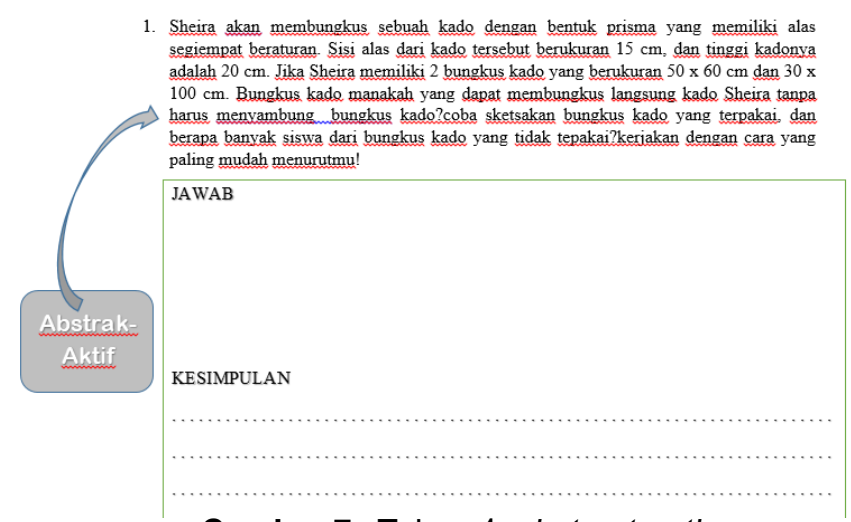

Gambar 7. Tahap 4: abstract-active

Masalah yang terdapat pada LKS BRSD tahap abstract-active berbeda dari permasalahan yang diberikan pada tahapan sebelumnya. Pada tahapan ini, siswa diberikan kebebasan untuk menyelesaikan permasalahan sesuai dengan apa yang mereka pahami. Siswa akan memberikan beragam jawaban dalam menyelesaikan masalah tersebut. Contoh jawaban siswa dalam menjawab LKS BRSD tahap abstract-active ditampilkan pada Gambar 8.

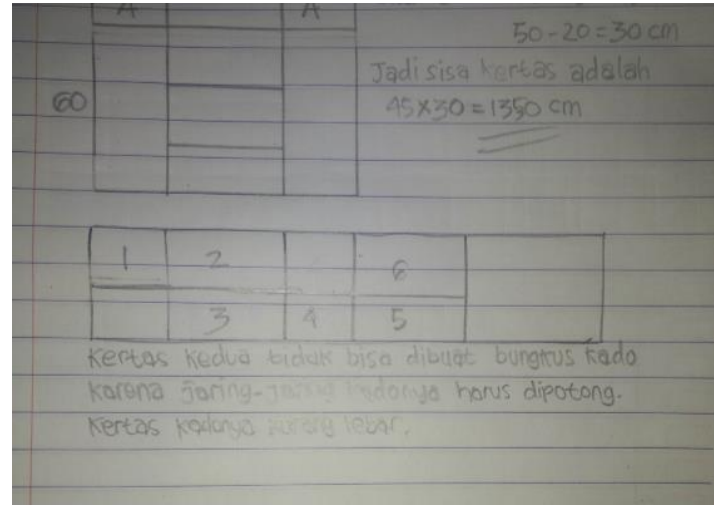

(a) Jawaban siswa S-1

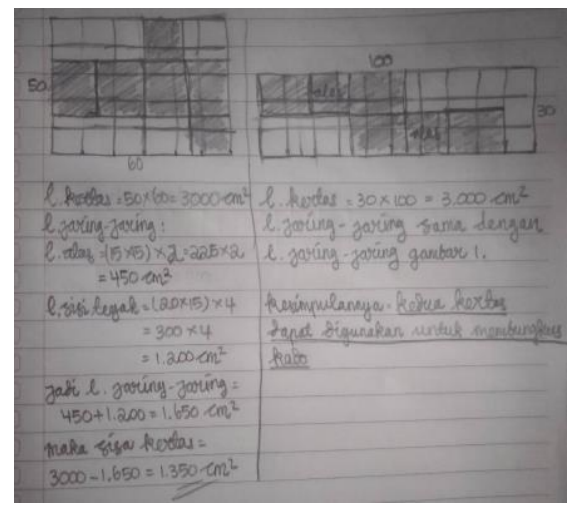

(b) Jawaban siswa S-2

Gambar 8. Contoh jawaban siswa

Berdasarkan Gambar 8 di atas, nampak dua jawaban siswa dalam menggambarkan jaringjaring serta penyelesaian permasalahan yang ditanyakan memiliki cara yang berbeda. Siswa pertama pada Gambar 8(a) menjawab kertas kado pertama dapat digunakan untuk membungkus kado, dan kertas kado kedua tidak dapat digunakan untuk membungkus kado. Akan tetapi, siswa kedua Gambar 8(b) menjawab bahwa kedua kertas kado dapat digunakan untuk membungkus kado. Pada tahap ini, siswa diarahkan untuk mengembangkan strategi individu dalam menyelesaikan 
masalah. Sehingga dapat dikatakan bahwa LKS BRSD dengan menggunakan model matematika Knisley dapat mengembangkan kemampuan berpikir siswa.

Sehingga nampak dari kedua jawaban pada Gambar 8 di atas, bahwa siswa akan mengembangkan pengetahuannya secara luas dan mengeksplor jawaban sesuai dengan apa yang dipikirkannya. Dengan demikian, dapat dikatakan bahwa pembelajaran dapat merangsang kompetensi siswa dalam berbagai aspek. Hal tersebut sesuai dengan pendapat Dedy et al. (2012) bahwa pembelajaran dengan menggunakan model matematika Knisley dapat meningkatkan kompetensi mahasiswa. Selain hal itu, terdapat pula respon siswa yang berkaitan dengan LKS BRSD dengan menggunakan model matematika Knisley dengan bantuan Geometryx. Respon ini merupakan bagian dari tahap restrospective analysis. Respon siswa didapatkan dari tiap isian siswa pada LKS di bagian kesimpulan tiap tahapannya ditampilkan pada Tabel 2.

Tabel 2. Respon siswa terhadap LKS BRSD dengan model matematika Knisley berbantuan Geometryx

\begin{tabular}{|c|c|c|c|c|}
\hline \multirow{2}{*}{ No } & \multirow[t]{2}{*}{ Indikator } & \multicolumn{2}{|c|}{ Respon Siswa } & \multirow[t]{2}{*}{ Keterangan } \\
\hline & & Positif & Negatif & \\
\hline 1 & $\begin{array}{l}\text { Isi LKS BRSD dengan model } \\
\text { matematika Knisley }\end{array}$ & $84 \%$ & $16 \%$ & $\begin{array}{l}\text { Mayoritas siswa berpendapat bahwa LKS yang } \\
\text { diberikan berbeda dari LKS biasanya dan } \\
\text { menjadikan mereka lebih banyak berpikir, } \\
\text { mencoba dan bereksplorasi secara positif. }\end{array}$ \\
\hline 2 & Penggunaan Geometryx & $91 \%$ & $9 \%$ & $\begin{array}{l}\text { Mayotitas siswa senang dengan Geometryx } \\
\text { karena mudah dan cepat }\end{array}$ \\
\hline & Rata-rata & $87,5 \%$ & $12,5 \%$ & \\
\hline
\end{tabular}

Berdasarkan data dari Tabel 2 di atas, terlihat bahwa mayoritas siswa memberikan respon positif terhadap LKS ataupun Geometryx. Siswa senang ketika kegiatan pembelajaran berbeda dari kegiatan pembelajaran yang biasa mereka lakukan. Selain itu, siswa dapat berpikir lebih banyak, sehingga kemampuan belajar mereka semakin baik. Sehingga dapat dikatakan bahwa model pembelajaran matematika Knisley dapat mengembangkan pemahaman konseptual. Berdasarkan respon siswa tersebut dapat dikatakan bahwa pembelajaran menggunakan LKS BRSD dengan model matematika Knisley dapat membuat pembelajaran menjadi bermakna, karena siswa dapat mengembangkan pengetahuannya dengan berbagai strategi. Hal tersebut sesuai dengan pendapat Johnston-Wilder (2016) bahwa mengembangkan dan membiasakan berpikir akan memngembangkan kebiasan berpikir konteks yang berguna dalam kehidupan sehari-hari. Hal tersebut sesuai dengan Allsopp et al. (2007) bahwa belajar matematika secara bermakna yaitu kegiatan pembelajaran yang membantu siswa menjadi pemikir kritis, mandiri dan memahami caracara dalam menerapkan solusi. Respon siswa terhadap terhadap penggunaan Geometryx ditampilkan pada Gambar 9.

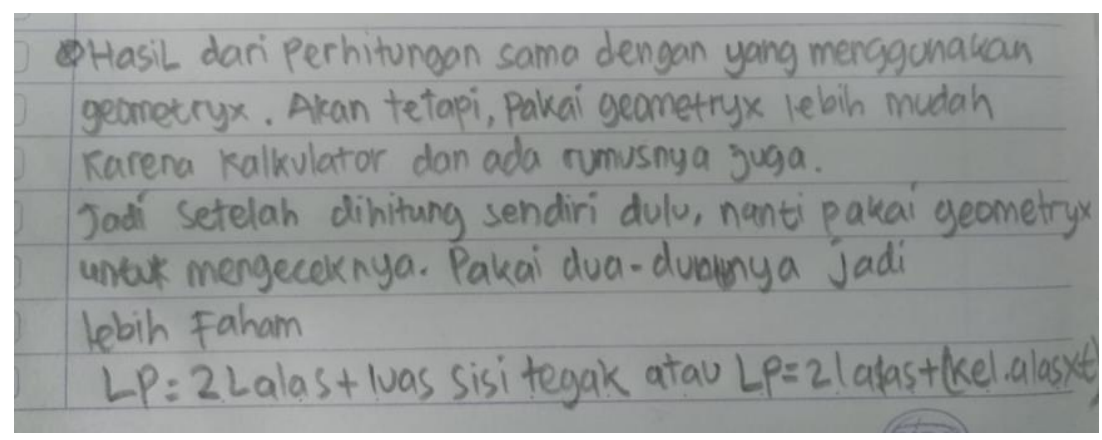

Gambar 9. Respon siswa terhadap penggunaan Geometryx

Pada Gambar 9 di atas, menunjukkan respon salah satu siswa yang memberikan gambaran terkait pembelajaran dengan Geometryx. Siswa tersebut mengemukakan bahwa Geometryx mudah diaplikasikan karena Geometryx seperti kalkulator. Sehingga dengan bantuan Geometryx siswa menjadi lebih mengerti mengenai materi yang diberikan. Geometryx dapat menjadi alat bantu dalam 
menyelesaikan masalah geometris untuk semua orang yang berhubungan dengan geometri, (https://play.google.com/store/apps/details?id=com.famobix.geometryx\&hl=in\&gl=US). Salah satu jawaban dan respon siswa terhadap terhadap penggunaan Geometryx ditampilkan pada Gambar 10.

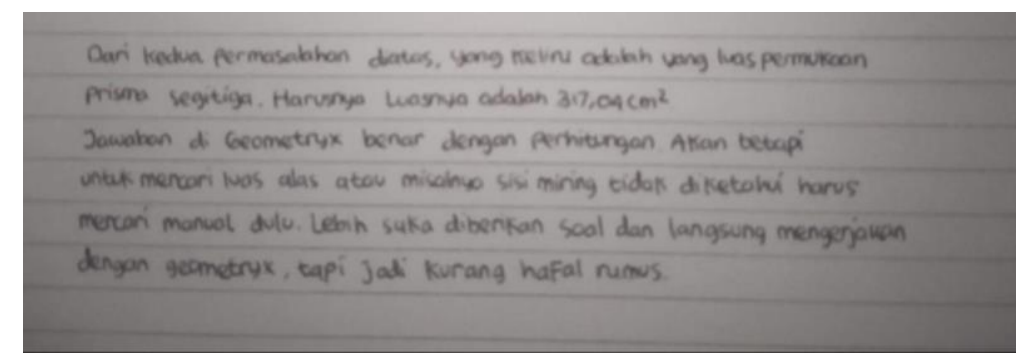

Gambar 10. Salah satu jawaban dan respon siswa terhadap penggunaan Geometryx

Respon siswa terkait penggunaan Geometryx beragam, dimana siswa berpendapat bahwa dengan Geometryx siswa menjadi tidak hafal rumus dan dapat lebih cepat mengerjakan soal. Selain hal itu, siswa juga mengungkapkan bahwa untuk mencari nilai awal dari luas alas harus mencari sendiri terlebih dahulu. Berdasarkan pendapat siswa tersebut dapat dikatakan bahwa pada tahap abstrak-reflektif dengan berbantuan Geometryx sangat tepat sekali.

Berdasarkan hasil yang diperoleh di atas, dapat dikatakan bahwa penggunaan aplikasi Geometryx tidak dapat digunakan sebagai tahapan dalam konstruksi pengetahuan, akan tetapi Geometryx berperan sebagai alat untuk mengecek kebenaran dari sebuah jawaban atau untuk mencari solusi dengan cara cepat. Idealnya, jika kegiatan pembelajaran dengan menggunakan Geometryx, siswa harus sudah memahami konsep terlebih dahulu, atau Geometryx digunakan sebagai alat untuk trial and error pada tahap kongkrit-aktif, sehingga siswa akan mencari data/sumber sebanyak-banyaknya. Karena siswa akan mencari data sebanyak-banyaknya, siswa sebagai analyzers, siswa akan membuktikan dan siswa akan berpikir lebih kritis lagi (Nurfauziah \& Sari, 2019).

\section{KESIMPULAN}

Berdasarkan hasil analisis data, didapatkan kesimpulan bahwa LKS BRSD dengan menggunakan model matematika Knisley berbantuan Geometryx berada pada kriteria valid dan tidak perlu direvisi. Namun, masukan dari validator terkait kesesuaian materi khususnya pada tahap concrete-reflective dan abstract-reflective telah diperbaiki sebelum diujicobakan kepada siswa. LKS BRSD dengan menggunakan model matematika Knisley berbantuan Geometryx mendapatkan respon positif dari siswa. Oleh karena itu, LKS BRSD dengan menggunakan model matematika Knisley berbantuan Geometryx dipandang dapat menjadikan pembelajaran matematika secara bermakna, karena dengan kegiatan pembelajaran tersebut, siswa dapat berpikir kritis, mandiri juga lebih eksploratif dengan adanya bantuan Geometryx yang memudahkan siswa dalam mengecek jawaban atau membuktikan ulang.

\section{REKOMENDASI}

Berdasarkan kesimpulan di atas, penulis dapat mengajukan rekomendasi sebagai berikut: (1) memperluas pandangan terkait materi BRSD yang tidak hanya dapat disajikan dengan cara biasa (dari pengertian, rumus, contoh dan latihan) menjadi lebih eksploratif dengan mengikuti tahapan dari model matematika Knisley disertai bantuan Geometryx; dan (2) mengembangkan bahan ajar materi lainnya dengan menggunakan model matematika Knisley berbantuan Geometryx.

\section{UCAPAN TERIMAKASIH}

Penulis mengucapkan terima kasih kepada IKIP Siliwangi Cimahi Jawa Barat yang telah menyediakan dana penelitian internal tahun 2020 dengan kategori Penelitian Kompetitif - Penelitian Dasar (PD). 


\section{DAFTAR PUSTAKA}

Abida, R., \& Kusuma, A. B. (2019). Pemanfaatan mobile learning pada pembelajaran matematika di era revolusi industri 4.0. Prosiding Sendika, 5(1), 229-235. Retrieved from http://eproceedings.umpwr.ac.id/index.php/sendika/article/view/716/614

Allsopp, D. H., Kyger, M. M., \& Lovin, L. H. (2007). Teaching mathematics meaningfully: Solutions for reaching struggling learners. Teaching mathematics meaningfully: Solutions for reaching struggling learners. Retrieved from http://unicat.bangor.ac.uk:4550/resserv?genre=book\&issn=\&title=Teaching+mathematics+me aningfully $\% 253 \mathrm{~A}+$ Solutions+for+reaching+struggling+learners.\&volume=\&issue=\&date=2007$01-$ 01\&atitle=\&spage=299\&aulast=Allsopp\&sid=ProQ:PsyclNFO\&isbn=1557668663\&jtitle=\&bti

Apriansyah, M. F., \& Pujiastuti, H. (2020). Pengembangan bahan ajar matematika berbasis virtual learning dengan gnomio. Jurnal Pendidikan Matematika, 11(2), 179. https://doi.org/10.36709/jpm.v11i2.11921.

Arikunto, S. (2010). Metode Penelitian. Jakarta: Rineka Cipta.

Awwalin, A. A. (2021). Analisis kesulitan siswa smp kelas viii pada materi bangun ruang sisi datar. 4(1), 225-230. https://doi.org/10.22460/jpmi.v4i1.225-230

Buana, D. R. (2020). Analisis perilaku masyarakat indonesia dalam menghadapi pandemi virus corona (covid-19) dan kiat menjaga kesejahteraan jiwa. SALAM: Jurnal Sosial dan Budaya Syar-I, 7(3). https://doi.org/10.15408/sjsbs.v7i3.15082.

CoSN. (2020). Covid-19 Response: Preparing to take school online.

Dedy, E., Mulyana, E., \& Sudihartinih, E. (2012). Berdasarkan model pembelajaran matematika knisley sebagai upaya meningkatkan kompetensi. Pythagoras, 7(1), 101-112. Doi: https://doi.org/https://doi.org/10.21831/pg.v7i1.2840.

Fatmawati, A. (2016). Pengembangan perangkat pembelajaran konsep pencemaran lingkungan menggunakan model pembelajaran berdasarkan masalah untuk sma kelas x. EduSains, 4(2), 94-103. Doi: https://doi.org/10.23971/eds.v4i2.512.

Haety, N. I., \& Mulyana, E. (2013). Pengaruh model pembelajaran matematika knisley terhadap peningkatan kemampuan koneksi matematis siswa sma. Jurnal Online Pendidikan Matematika Kontemporer, 1(1), 1-8.

Johnston-Wilder, S. (2016). Learning to teach mathematics in the secondary school. Learning to Teach Mathematics in the Secondary School. https://doi.org/10.4324/9781315672175

Knisley, J. (2000). A four-stage model of mathematical learning. Journal of the Learning Sciences, (423).

Knisley, J. (2002). A four-stage model of mathematical learning. Jurnal. online. http://citeseerx.ist.psu.edu/viewdoc/download?doi=10.1.1.324.522\&rep=rep1\&type=pdf

Lamote, H. (2017). Kesulitan-kesulitan guru matematika dalam melaksanakan pembelajaran 
kurikulum 2013 di madrasah aliyah ddi labibia. Jurnal Al-Ta'dib, 10(1), 56-72. https://doi.org/10.1017/CB09781107415324.004

Nurfauziah, P., \& Sari, V. T. A. (2019). Penerapan bahan ajar trigonometri dengan model matematika knisley untuk meningkatkan kemampuan berpikir kritis matematik mahasiswa. AKSIOMA: Jurnal Program Studi Pendidikan Matematika, 7(3), 356. https://doi.org/10.24127/ajpm.v7i3.1551

Prahmana, R. C. I. (2017). Design research (Teori dan implementasinya: Suatu pengantar). Rajawali Pers.

Romadoni, E. M. C. (2016). Implementasi model pembelajaran matematika knisley (mpmk) dalam upaya meningkatkan. Prosiding Universitas Muhamamadiyah Surakarta, (Knpmp I), 570-579.

Salirawati, D. (2006). Penyusunan dan kegunaan lks dalam proses pembelajaran. Makalah Dipresentasikan pada Kegiatan Pengabdian kepada Masyarakat, UNY Yogyakarta. Retrieved from https://scholar.google.co.id/scholar?cluster=9910012516550974052\&hl=id\&as_sdt=0,5

Tim Kerja Kementerian Dalam Negeri. (2020). Pedoman umum menghadapi pandemi covid-19 bagi pemerintah daerah: pencegahan, pengendalian, diagnosis dan manajemen. Journal of Chemical Information and Modeling, 53(9), 1689-1699. https://doi.org/10.1017/CB09781107415324.004

Tusiah, \& Amalia, S. (2018). Identifikasi kesulitan belajar siswa smp dalam memahami konsep luas dan volume limas. Prosiding Seminar Nasional Pendidikan Matematika, 1(1), 378-389.

Unicef. (2020). Covid-19 emergency preparedness and response wash and infection prevention and control measures in schools.

White, T., \& Martin, L. (2014). Mathematics and Mobile Learning. TechTrends, 58(1), 64-70. https://doi.org/10.1007/s11528-013-0722-5

Zinnurain, \& Gafur, A. (2015). Pengembangan multimedia pembelajaran matematika pada materi bangun ruang sisi datar untuk siswa smp kelas viii. Jurnal Inovasi Teknologi Pendidikan, 2(2), 157-168. Retrieved from http://journal.uny.ac.id/index.php/jitp\%OAPENGEMBANGAN 